\title{
Tracing National and Global Forces in a Taiwanese SME's Product Innovation
}

\author{
TOMMY TSUNG YING SHIH
}

\begin{abstract}
Taiwan's competitiveness in the global arena has often been attributed to the country's dynamic small and medium-sized enterprises (SMEs). In the most recent decade, the Taiwanese government has increased support to innovative SMEs, and with the emergence of new fields such as biotechnology, companies with highly innovation-driven agendas are surfacing. The innovation focus provides not only new opportunities but also challenges for Taiwanese SMEs. In this article I aim to increase the understanding of how national and global forces affect SME innovation in Taiwan. To this end, I use an industrial network approach to trace the national and global interdependencies that follow the network of a Taiwanese SME in the biopharmaceutical sector.
\end{abstract}

Keywords: SME, innovation, network, Taiwan, triangulation

\section{Introduction}

Taiwan's economic development is an impressive story. In just a few decades, the country has transformed itself from an agrarian society into an advanced high-tech economy (World Bank 1993; Amsden \& Chu 2003). This transformation is highly associated with the country's dynamic small and medium-sized enterprises (MOEA 2010). During the 1970s and 1980s, when Taiwan commenced the transition into high-tech fields such as electronics and semiconductors, the SMEs were in the forefront of the global expansion (Chang, Shih \& Hsu 1994; Mathews \& Cho 2000). In the 1990s, with the emergence of the Taiwanese biotechnology sector, SMEs were yet again at the centre of attention. Although some SMEs have managed to develop new products and technologies, they have had difficulty finding markets, local as well as global, for their products (Hsu, Shyu \& Tzeng 2005). For example, in 2007, the production output of the biotechnology industry was valued at roughly 6 per cent of what was produced in the semiconductor sector (MOEA 2008). Some observ- 
ers argue that such a number illustrates the failure of biotechnology in Taiwan (Hsu et al. 2005). Others claim that it is too early to judge how this industry will develop in the future (Wong 2005). Regardless, the Taiwanese government has continued to heavily support the build-up of a homegrown biotechnology industry. This effort is contingent on the creation of innovative capabilities among SMEs and their integration into global production networks (Ernst 2010; MOEA 2007). Hence, the recent developments are guided by a proactive government policy that seeks to indigenize innovation. By promoting the public research system, supporting SMEs and introducing various technology transfer mechanisms, the Taiwanese government has aimed to build local innovation networks (Dodgson, Mathews, Kastelle \& Hu 2008). The subsequent step in this model is to aid these networks in establishing ties to global markets (Liu 1993). The present study posits that the model oversimplifies the issue of innovation development and commercialization.

Taiwanese SMEs in the biotechnology sector are, on the one hand, affected by a national policy environment, which seeks to indigenize innovation and retain investments within national borders. Taiwanese innovative SMEs, on the other hand, are already often embedded within global innovation networks (Ernst 2010). Hence the national environment can hamper innovative activities, as the logic of local industrial policy is frequently different from the logic of global innovation networks. Such conflicts are, however, not uncommon. Jacobsen (2010) points out that there has been a trend of decoupling the nation-state from the global community. This is a highly impractical practice, as SMEs innovate in a local-global environment. As Kneller (2010) notes, SMEs are particularly important in the upstream part of the global biotechnology value chain. Hence, in order to understand SME innovation in the Taiwanese context, we need to not only understand the domestic forces at play but also the global forces that shape company behaviour. To investigate the interplay between global and local forces, and their effects on SME innovation, I build on the idea of triangulation proposed by Jacobsen (2010) and Chin (2010). According to Jacobsen (2010: 2), triangulation infers that 'the relationship between economic globalisation, national economics and a given societal context in which the two former are embedded is governed by various layers of interdependency'. In this study, I conceptualize the three dimensions through the lens of the industrial marketing approach (Håkansson \& Snehota 1995). In this perspective, the social context is the network of actors within which an SME is embedded. As industrial networks stretch across national and 
global boundaries, this also allows for the investigation of various local and global forces that affect the innovative activities of a focal firm (Håkansson, Ford, Gadde, Snehota \& Waluszewski 2009).

The present study contributes to the empirical understanding of Taiwanese SME innovation in the biopharmaceutical sector. It also builds on the industrial marketing literature by developing a conception of how national and global forces affect SME innovation in a network environment. The global and local contexts represent two distinct environments, upon which the focal firm and its network are dependent in order to innovate. Hence, a separation of these two dimensions is relevant to understand how Taiwanese SMEs innovate. This article uses a single case study approach, following a Taiwanese biotechnology company, to illustrate SME innovation in the local-global context. The next section presents the theoretical framework, based on the industrial network approach. Thereafter I present the method, followed by the introduction of the empirical case study. The analysis then discusses the influences of national and global forces on the focal firm's innovative activities. Lastly, the findings and implications of this study are discussed.

\section{Theoretical Framework}

\section{Networks and SME Innovation}

Innovation as an interactive phenomenon has been widely described (e.g. Lundvall 1988; Chesbrough 2003; Håkansson \& Waluszewski 2007). This study approaches innovation in the SME context from an industrial network perspective (Ford, Gadde, Håkansson \& Snehota 2003). Innovation through networking is particularly important for SMEs as small size and lack of resources put them at a disadvantage in the development and commercialization of innovation. For example, SMEs frequently face difficulties in access to markets, capital and skilled labour (Kaufmann \& Tödtling 2002; Harvie \& Lee 2002; OECD 2010). As such, SMEs are often dependent on their networks for access to various resources involved in the development and commercialization of innovations (Fuller-Love \& Thomas 2004). Hence, in the SME context, resource combinations beyond company borders are of particular importance as companies frequently lack the resources to single-handedly develop and commercialize innovations (Narula 2004). Moreover, as companies seek complementary resources they often find themselves working with business and nonbusiness actors, both in the home country and abroad. Thus, a network 
view can aid in explaining and illustrating interdependencies created between national and global forces in a societal context. This study investigates, in particular, the effects of global and national interdependencies on SME innovation.

\section{Tracing National and Global Interdependencies in a Network Context}

This research is based on the industrial network approach (Håkansson 1982). In this approach, a network is made up of three interrelated dimensions: actors, resources and activities (Håkansson \& Snehota 1995). Interaction over time in a network establishes interdependencies and adaptations that create imprints on both the human and material resources involved. This phenomenon, over the last few decades, has interested a great number of researchers (see e.g. Rosenberg 1994; van de Ven, Polley, Garud \& Venkataraman 1999; Ford et al. 2003; Håkansson et al. 2009). With interdependencies in the business landscape as a focus, empirical investigations of the content and effect of this phenomenon have been carried out, among others, by researchers related to the industrial network approach (e.g. Håkansson \& Waluszewski, 2002; Waluszewski, Baraldi, Linné \& Shih 2009; Strömsten \& Håkansson 2007; Shih 2009).

In theory, industrial networks can extend endlessly; they are not geographically bounded (Ford, Gadde, Håkansson \& Snehota 2002). Hence the different institutional logics (Thornton 2002) that a firm encounters through its network activities derive from national as well as global environments. This study examines the national institutional context as well as the global industrial networks within which the focal SME is embedded. These two contexts form a specific conception of the national and global forces that affect SME innovation in Taiwan. On the one hand, a company is influenced by norms, rules and institutionalized ideas from the national context (Forsgren 2008). On the other, a company has to confront the norms and value systems of global production networks (Levy 2008). Embedded within these forces, SMEs manage innovation and confront the logics of institutions, business and non-business actors.

\section{Analytical Framework}

The analytical framework traces the network relationships, i.e. the actor bonds, resource combinations and the activity links, of a focal company (Håkansson \& Snehota 1995). The network of actors is then divided into actors that the focal firm relates to in a national context and 
FIGURE 1: Analytical framework

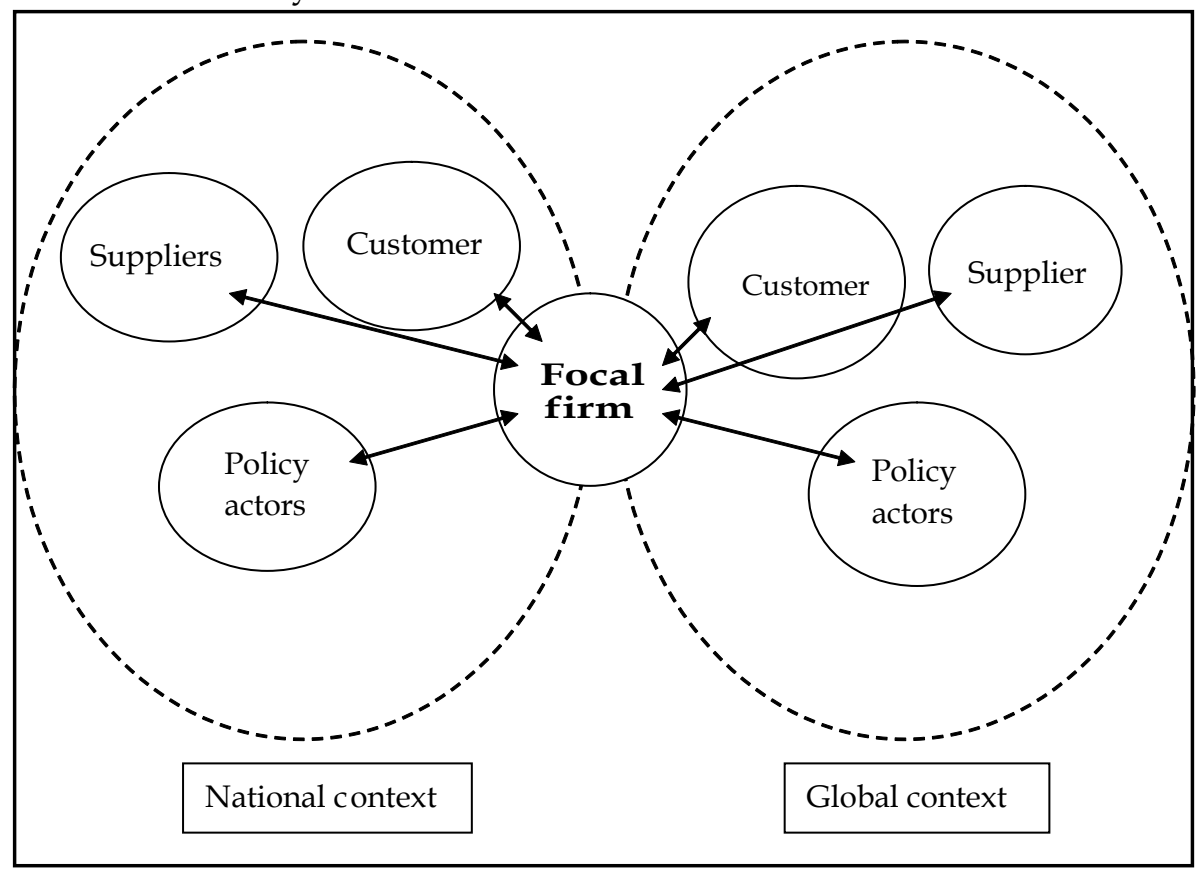

a global context respectively. The present study posits that the different environments pose and offer different challenges and opportunities for the focal firm, that is, the norms and institutionalized ideas and logics within each environment are different to a greater or lesser degree (DiMaggio \& Powell 1983). Through the bifurcated distinction, the interdependencies created in the two contexts can be separated, but they also aid in understanding how the different environments affect the focal company's innovative activities. The figure above illustrates the analytical framework.

\section{Method}

This paper adopts a single case study methodology. Case studies enable the research of details on activities and relationships (Holmlund 2004). In the industrial network tradition, case studies are heavily utilized to exemplify diverse empirical phenomenon. Easton (1998) argues that the usefulness is due to the richness of the picture produced by case research and the approach is suited to handle the complexity of network links among actors. Researchers can also suitably use case studies when exploring interaction and tracing the development of network changes over time (Dubois and Araujo 2004). 
The case portrays the innovation journey of a Taiwanese biotechnology company and the challenges and opportunities it faces in its innovation environment. The case findings will be used in a broader discussion on the innovation environment of Taiwanese biopharmaceutical companies. The empirical material that the case study builds on was collected in the period 2004-2008. In the case study I use so-called 'rich descriptions' (Walsham 1995) by combining interviews with secondary material retrieved from the company and its website, and other printed material. Interviews are the major source of information. This paper is based on 24 face-to-face interviews of 17 respondents. The average duration of the interviews was approximately one hour and all interviews were conducted in Taiwan. The respondents interviewed had different organizational affiliations, including policy organizations, universities, research institutes and companies. Respondents were identified through snowball sampling. The secondary sources include materials such as official policy documents, articles from academic journals and newspapers, industry reports, websites, transcribed speeches and statistical material. The secondary sources identify events and establish timelines and give varied perspectives of the development processes studied. Sometimes they have functioned as a single source of information to describe a development process and give voice to resources. Other times the secondary sources have helped to deepen and substantiate the picture given by interviewees.

\section{Case Study}

The case study focuses on the development and commercialization of biopharmaceutical drugs in Taiwan. The first section describes how the focal company innovates in the Taiwanese context. The second section focuses on its innovative activities in a global context.

The focal actor of this study is a medium-sized biopharmaceutical company with 60 employees (2008), the Taiwan Liposome Company (hereafter TLC). The company was established in 1997 as a university start-up and its main business activities are liposome drug delivery and proprietary drug development. Liposome drug delivery centres on making existing pharmaceutical drugs more efficient by finding solutions to improve the ways the human body can absorb the drug (Haumann 1995). Through this business idea, TLC, together with partner companies, has developed a generic pharmaceutical drug for the Taiwanese market. The company has four additional drug candidates in its development pipeline. Recently TLC also moved into novel drug development, i.e. 
the development of patentable drug candidates through a partnership with foreign actors. Although drug innovation is desired and supported by Taiwanese policymakers, the established healthcare and regulative systems are not able or willing to bring forward novel drugs in Taiwan. The following case illustrates the influences of national and global forces, including the interplay between them, on TLC's innovative activities.

\section{Development of Biopharmaceutical Drugs Embedded in a National Ambition to Create a Biotechnology Industry}

The biotechnology sector has since the mid-1990s been on the Taiwanese government's list of potential industries that can move Taiwan into the league of advanced innovative nations. This focus on biotechnology has meant extensive support to basic research as well as to the ind ustrial sector. Up to 2007, 265 companies had been established in the biotechnology sector, focusing on areas such as drug development, medical technology and clinical testing (MOEA 2008). Such a development coincides with the expansion of science parks and the establishment of research institutes aimed at developing certain fields of biotechnology relevant for Taiwan and its industrial sector. It is within this environment that TLC was formed in 1997 by Dr Keelung Hong. The company started out with a group of five researchers at the National Taiwan University, led by Hong. The initial idea of the group was to encapsulate a drug for cancer based on the drug delivery system that the group had developed. The choice of what off-patent drug to apply the delivery system to was made by Hong. His experience with earlier drug developments in the United States, closely related to what TLC was attempting, was beneficial for the company's growth.

At this time only a handful of Taiwanese companies were involved in drug development, not including the generic drug manufacturers. TLC raised start-up capital mainly from friends and family, but was unsuccessful in obtaining funding from Taiwanese government sources. The main reason why TLC did not receive any financial support from the government was due to a perceived lack of novelty of the proposed project. Nonetheless, TLC managed to go through pre-clinical trials with a small purse by utilizing university laboratories and Hong's prior experience from a similar project. After the necessary regulatory approvals of safety and efficacy had been attained, the next step was to start clinical trials. The Taiwanese regulatory environment and the institutional framework are streamlined for such tests of generic drugs, and few obstacles are to be found if approval from the authorities ex- 
ists. However, a problem was identified in the lack of connections to pharmaceutical producers, as a large quantity of the active ingredient of the drug was needed.

The problem was eventually solved when TLC entered into a partnership with one of the largest local pharmaceutical producers, TTY Pharmaceuticals. The company licensed the rights to TLC's drug candidate and also continued with clinical testing. By the millennium shift, TTY had finished the clinical trials and introduced the drug on the Taiwanese market after the Taiwanese drug authorities had approved it for use. TLC followed this line of developing generic drugs for the subsequent drug candidates. Two more drug candidates were developed and licensed by TLC in a similar fashion. For this development, Taiwan's Ministry of Economic Affairs gave TLC an award as 'high-tech entrepreneur of the year' in 2002. TLC represented an example of how a national network of universities, government research institutes and industrial actors jointly had developed and commercialized pharmaceutical drugs. By 2008, TLC had with its domestic partners launched one biopharmaceutical drug on the Taiwanese market and four others were being developed (see Table 1).

TABLE 1: Product pipeline, Taiwan Liposome Company (2008)

\begin{tabular}{|l|l|l|l|}
\hline Product & Technology & Phase & Partnerships \\
\hline Dox & $\begin{array}{l}\text { Underlying drug: } \\
\text { Doxorubicin. Liposome } \\
\text { formulation developed by } \\
\text { Keelung Hong }\end{array}$ & $\begin{array}{l}\text { Out on market, approved for } \\
\text { treatment of ovarian cancer and } \\
\text { Kaposi's sarcoma by the DOH } \\
\text { 2002. Sales of 90 million NTD } \\
(2004)\end{array}$ & $\begin{array}{l}\text { Licensed to } \\
\text { TTY Pharma- } \\
\text { ceuticals for } \\
\text { production } \\
\text { and sales }\end{array}$ \\
\hline Lipo AB & $\begin{array}{l}\text { Underlying drug: } \\
\text { Amphotericin B Liposome } \\
\text { formulation developed by } \\
\text { Keelung Hong }\end{array}$ & Clinical trials phase 2 & $\begin{array}{l}\text { Licensed to } \\
\text { TTY Pharma- } \\
\text { ceuticals for } \\
\text { production } \\
\text { and sales }\end{array}$ \\
\hline Nano & $\begin{array}{l}\text { Underlying drug: } \\
\text { Vinorelbine NanoX, licensed } \\
\text { from Hermes (Keelung Hong } \\
\text { co-developer) }\end{array}$ & $\begin{array}{l}\text { Licensed to } \\
\text { Nankuang } \\
\text { Pharmaceu- } \\
\text { ticals }\end{array}$ \\
\hline TLC 188 & $\begin{array}{l}\text { Dual function technology, } \\
\text { NCE California Pacific Medi- } \\
\text { cal Center owner of the patent } \\
\text { Yang) }\end{array}$ & $\begin{array}{l}\text { Filed patent 2005, Filed for IND } \\
\text { Q3, 2006. Currently in pre-clini- } \\
\text { cal trials }\end{array}$ & No \\
\hline $\begin{array}{l}\text { TLC } \\
\text { X88 }\end{array}$ & $\begin{array}{l}\text { Dual function technology, } \\
\text { NCE } \\
\text { Underlying drug: } \\
\text { Camptosar: Camptothecin } \\
\text { analogue, California Pacific } \\
\text { Medical Center owner of the } \\
\text { patent. } \\
\text { Yang) }\end{array}$ & Pre-clinical & No \\
\hline
\end{tabular}


However, the story does not end here and the picture is not as rosy as it appears. The companies involved in the discovery and development of novel drugs in Taiwan are still few in number. The local pharmaceutical industry consists mainly of generic drug manufacturers catering predominantly for a local market. They generate their main income from drug reimbursements by the national health insurance system. With the health insurance system as the main source of income for a large number of local generic drug manufacturers, they are heavily dependent on the prescribers of drugs. Taiwanese healthcare providers such as hospitals and clinics have usually formed stable relationships with the generic drug manufacturers. Due to the healthcare providers' power on the local market governing the prescription of drugs, the drug manufacturers are in a dependent position. They often sell drugs to the healthcare providers at a discounted price. The margin between the selling price and what the national health insurance system reimburses goes directly to the healthcare providers. Thus, the healthcare providers have tended to prioritize profits ahead of efficacy. This means that novel drug innovations that sell at a premium are not easily embedded in the existing healthcare system.

However, attempts to change the system are ongoing. For example, the Taiwanese government's measures to reform the inefficient reimbursement system have resulted in a decrease in the number of generic drug manufacturers. In 2006, the pharmaceutical sector had decreased by 51 companies from a year earlier, to 368 companies. At the same time, the number of research-based pharmaceutical and biotechnology companies developing novel drugs or modifying existing drugs for new uses has increased in the last decade. However, no Taiwanese company has yet developed and produced a novel drug (MOEA 2008). To understand this challenge I will continue by broadening the picture by discussing the challenges and opportunities that TLC has faced in the global context.

\section{Transcending National Boundaries in the Search for Product Innovation}

The history of liposome technology starts in Cambridge, England, in 1965, where it was discovered by a group of scientists. In the 1970s scholars, mostly in the United States, especially the San Francisco/Silicon Valley area, suggested that these discoveries could lead to the development of new ways of delivering drugs. However, it was not until the 1990s that clinical applications developed by a handful of American biotechnology companies became available. It was within this environment 
that Hong was active as a researcher and industrial consultant from the 1970s to the 1990s. Hence he had acquired experience of clinical drug development and was also knowledgeable of the frontiers of liposome science. When he returned to Taiwan to teach, and later form TLC, he was a pioneer and authority within liposome research and business. This also meant that TLC was from the beginning embedded in a global research network. TLC's knowledge of liposome science and clinical applications were derived from this network.

The assistance from the policy-supported Taiwanese environment was related to cheap laboratory and office space at the National Taiwan University and Nankang Software Park in Taipei. Taiwan also provided for the production of drugs and clinical testing. The actual knowledge of drug development and the ambition to innovate was, however, strongly embedded in a global network. For example, to develop or acquire multiple technology platforms was an essential strategy to be able to develop more drugs. When TLC pursued such a strategy in the beginning of the new millennium, the company sought alliances in the United States. Neither Taiwanese companies nor the public research system had any extensive experience with drug delivery systems. Moreover, the assistance offered from the Nankang incubation centre and the Taiwanese government research institutes was limited. The main technology partner for TLC was Hermes Biosciences located in San Francisco. Hong had co-founded Hermes Biosciences in 1998 and licensed the rights to use a proprietary technology platform from the company. The technology could be combined with existing drugs as well as new chemical compounds.

In 2005 TLC moved in the new direction of novel drug development. The company filed two new patents, which would serve as a foundation for a new line of novel drug candidates. The two patents had originally been developed at California Pacific Medical Center (CPMC) from discoveries made by Professor Li Xi Yang. At CPMC, Yang conducted research on a group of anti-cancer agents. The research had resulted in the synthesis of a new chemical compound classified as a novel discovery. Yang agreed to become a vice president of TLC and head the company's American subsidiary. The mission of the subsidiary, TLC Biopharmaceuticals, was to develop a new line of novel drugs, founded on Yang's discovery of a new compound and TLC's proprietary liposome technology. The decision to move development to the United States was also a conscious choice to overcome the bottlenecks in Taiwan's drug approval system. While generic drugs enjoy a streamlined process from 
clinical testing to marketing, this is not the case for novel drugs in Taiwan. No novel drugs have ever been approved in Taiwan. This creates a dilemma, as no established routines exist, resulting in difficulties in evaluating new drug applications. To handle novel drug developments in the United States is therefore a better choice for drug discovery and developing companies.

Although TLC's establishment of an American subsidiary increased costs considerably, it had several advantages. The company could conduct innovative activities in an environment with a developed infrastructure and regulatory system for drug development. Even before establishing the American subsidiary, TLC frequently interacted with US-based companies, research organizations and researchers. The headquarters of the company is still, however, in Taiwan, where expenses are much lower than in the United States. In Taiwan, the company has been able to keep the costs down through lower salary levels and low facility costs. Conducting clinical trials in Taiwan has also been favourable as patients are generally positive towards trying out new drugs and the government is aiming to establish Taiwan as a clinical trials centre for Asia. Hence, TLC plans to keep the main research and development activities in the US, where the experienced biopharmaceutical researchers are found. It is also easier to get a novel drug approved in the United States than in Taiwan, due to the experience of the Food and Drug Administration in evaluating novel drugs. The production of the drug and the active ingredients will be done in Taiwan, through the established connections with Taiwanese pharmaceutical companies. In 2010, TLC also established TLC Biopharmaceuticals BV, a subsidiary located in Leiden, the Netherlands, to be able to work within the European regulatory system and develop new drugs for the European market. As in the United States, Europe has an advanced drug development system conducive for drug innovation. The recent developments and focus on innovative drug research and development have enabled TLC to establish a partnership with TEVA Pharmaceutical Industries, the largest generic drug manufacturer in the world. The relationship allows TLC to embed within a global production network.

\section{Analysis}

The following analysis describes the network in which TLC is embedded in order to innovate. Figure 2 portrays the company's existing network in global and national contexts. 
FIGURE 2: TLC's Innovation Network in a National and Global Context

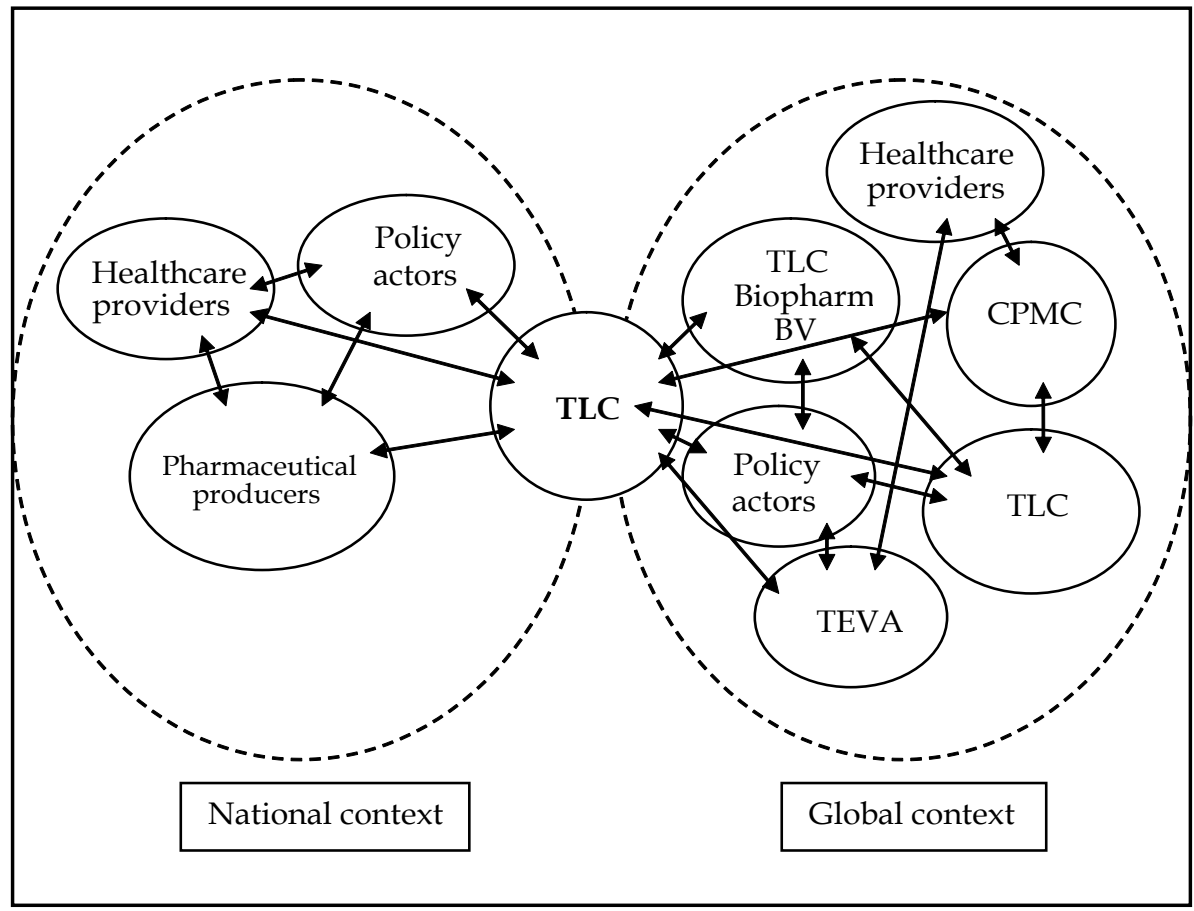

In the national context, TLC focuses on generic drug development and incremental innovation. The support from the government enables the company to pursue development of drugs that can easily embed within the established structures. However, the established actors in the Taiwanese pharmaceutical sector stifle radical innovation through their heavy investments in present structures. The dominant business model in the pharmaceutical industry is to provide generic drugs to healthcare providers at a low price. In such an environment there are few possibilities and low tolerance to innovate outside of the system. The environment in Taiwan does not allow for any innovation that drastically changes the structure of the sector.

To pursue radical innovation, TLC sought assistance outside of the national environment. In the United States, knowledge, technology and a conducive institutional context were available. The founder's prior scientific and business contacts in the US enabled TLC to embed within the American drug development system. The choice to circumvent the bottlenecks in Taiwan by moving to an environment conducive for radical innovation was a necessary step. However, this also puts TLC in a more vulnerable position as the company faces higher cost structures and lack of legitimacy. 
The interplay between the two environments becomes in this situation an important aspect. The low cost of production and clinical testing in Taiwan remains an important part of TLC's business model. This part integrates with the development of novel drugs in a global environment that allows for radical innovation. TLC's establishment of a business model that can combine radical innovation with incremental innovation has helped the company to embed within a global production network.

\section{Discussion and Conclusions}

In the last decade, Taiwan has focused on replacing the label 'made in Taiwan' with 'innovated in Taiwan'. To facilitate this transition, the Taiwanese government has supported and guided research organizations and companies in their innovative activities. SMEs play an integral role in developing and commercializing innovations, particularly in new industrial sectors such as biotechnology. Their success or failure in innovation is not only affected by internal company factors but also by the larger environment in which they act. This article has followed a Taiwanese SME in the development of biopharmaceutical drugs. Although the company is not necessarily representative of Taiwanese high-tech SMEs, the case demonstrates how national and global environments impact the development and commercialization of innovations. Industrial network theory, as an analytical lens integrating national and global forces, aids in increasing the understanding of the challenges and opportunities Taiwanese SMEs face in their innovation journeys.

An apparent challenge in the national context as illustrated in this case, is the conflict between the policy aim of supporting innovative SMEs in the biotechnology industry on the one hand, and the immature drug approval system in Taiwan on the other. It is evident in this regard that social policy and industrial policy have not been considered together. While government promotion of innovation has strengthened the development pipelines of small and medium-sized drug developers, the drug approval system and national health system hamper biopharmaceutical innovation. This obvious conflict makes it difficult for Taiwanese drug developers to develop innovative drugs for a domestic market. The complexity of innovation, however, goes well beyond this simple clash. The focal company's innovation journey is highly embedded in a network that is global. The case suggests that while globalization intensifies competitive pressure on SMEs in national 
and global arenas, it also gives SMEs opportunities to access resources transcending national borders.

Thus, globalization is a double-edged sword that requires explicit attention. In the Taiwanese policy context, this phenomenon is still not well understood. Let us take the example of Taiwanese policymakers' endeavour to build up national innovative capacity, where it is envisioned that the national supply of ideas and inventions are to be used and commercialized by local SMEs. However, how does the observation that innovation networks are highly global come into practice in this idealized desire to achieve independent national innovation? From the case study, it is evident that it is not easy for policymakers to control or dictate the geographical dispersion and direction of innovation. Doing so would likely be counterproductive, as the nature of innovation is characterized by a high degree of serendipity. Hence, if we take a more descriptive stance rather than a normative one, we can understand through the applied framework the ramifications of national SME policy in the context of globalization.

I have in this article aimed to increase the understanding of how national and global forces affect the environment for SME innovation in Taiwan. It was observed that national innovation policy often conflates innovative capability with innovation per se. For example, effective intellectual property regimes and the government's commitment to support local upstream research and SMEs, for instance, are seen to be key policy instruments to facilitate technological innovation processes. Research and development is highly global in nature and putting more effort into supporting global developing networks could benefit policy attempts to strengthen national innovation. However, as this study illustrates, research and development is only one part of the innovation journey; policymakers also need to consider that an innovation needs to be embedded in streamlined regulatory and market systems. The contexts seem to be driven by different institutional logics, and are also less affected by the forces of globalization until recently in Taiwan.

Lately, pharmaceutical suppliers have viewed the emergence of innovative SMEs as a channel to gain competitiveness and enter foreign markets. This offers biotechnology SMEs an opportunity to commercialize their discoveries. Nonetheless, for the biotechnology SME environment to be truly conducive to innovation, the major discord with the national market setting needs to be remedied. This will be a considerable challenge as this setting is characterized by well-established structures with social and economic relationships negating the efforts 
of SMEs to innovate. Hence for SME s to innovate it is necessity to find opportunities to work within the national context, but also to be able to transcend the constraints that are posed by this environment. As in the case of the focal company in this study, constraints led the company to seek opportunities outside of the national context and to finds ways to combine national and global opportunities. This is a challenge but also a necessity for companies to be truly innovative in the Taiwanese biopharmaceutical sector.

Tommy Tsung Ying Shih received his PhD in Business Studies from Uppsala University in Sweden. He is currently a Research Fellow at the Centre for East and Southeast Asian Studies at Lund University in Sweden. His research focuses on industrial development, innovation and business networks in Taiwan and China. Email: tommy.shih@ace.lu.se

\section{REFERENCES}

Amsden, A. and W. W. Chu. 2003. 'Beyond Late Development: Taiwan's Upgrading Policies'. Cambridge, MA: MIT Press.

Chang, P.L., C.T. Shih and C.W. Hsu. 1994. 'The formation process of Taiwan's IC industry: Method of technology transfer'. Technovation 14(3): 161-171.

Chesbrough, H. 2003. ' Open Innovation: The New Imperative for Creating and Profiting from Technology'. Boston: Harvard Business School Press.

Chin, Y.W. 2010 'Repositioning Malaysian SMEs in the global economy: Economy, society, and the state'. Paper at the international workshop, 'Global Economics and the SME Business Environment in East and Southeast Asia: Opportunities and Constraints', 30 Sept. - 1 Oct. 2010, Copenhagen, Denmark.

DiMaggio, P., and W. Powell. 1983. 'The iron cage revisited: Institutional isomorphism and collective rationality in organizational fields'. American Sociological Review 48(2): 147-160.

Dodgson, M., J. Mathews, T. Kastelle, and M.-C. Hu. 2008. 'The evolving nature of Taiwan's national innovation system: The case of biotechnology innovation networks'. Research Policy 37(3): 430-445.

Dubois, A., and L. Araujo. 2004. 'Research methods in industrial marketing studies'. In Rethinking Marketing: Developing a New Understanding of Markets, H. Håkansson, D. Harrison, and A. Waluszewski (eds.), pp. 207-228. Chichester: John Wiley and Sons.

Easton, G. 1998. 'Case research as a methodology for industrial networks: A realist apologia'. In Network Dynamics in International Marketing, P. Naudé and P. Turnbull (eds.), pp. 73-87. Oxford: Pergamon Press.

Ernst, D. 2010. 'Upgrading through innovation in a small network economy: Insights from Taiwan's IT industry'. Economics of Innovation \& New Technology 19(4): 295-324.

Ford, D., L.-E. Gadde, H. Håkansson, and I. Snehota. 2002. 'Managing Networks'. Paper presented at the 18th IMP Conference, 11 - 13 December 2002, Perth, Australia.

Ford, D., L.-E. Gadde, H. Håkansson, and I. Snehota. 2003. 'Managing Business Relationships'. Chichester: Wiley and Sons. 
Forsgren, M. 2008. 'Theories of the Multinational Firm. A Multidimensional Creature in the Global Economy'. Cheltenham: Edward Elgar.

Fuller-Love, N., and E. Thomas. 2004. 'Networks in small manufacturing firms'. Journal of Small Business and Enterprise Development 11(2): 244-253.

Harvie, C., and B.C. Lee. 2002. 'Globalisation and SMEs in East Asia'. Cheltenham: Edward Elgar.

Haumann, B.F. 1995. 'Liposomes offer hope as medical tools'. Inform 6: 793-802.

Holmlund M. 2004. 'Analyzing business relationships and distinguishing different interaction levels'. Industrial Marketing Management 33(4): 279-287.

Hsu, Y.G., J. Shyu, and G.H. Tzeng. 2005. 'Policy tools on the formation of new biotechnology firms in Taiwan'. Technovation 25(3): 281-292.

Håkansson, H., (ed.), 1982. 'International Marketing and Purchasing of Industrial Goods - An Interaction Approach'. New York: Wiley.

Håkansson, H., and I. Snehota (1995) 'Developing Relationships in Business Networks'. London: Routledge.

Håkansson, H. and A. Waluszewski 2002. 'Managing Technological Development. IKEA, the environment and technology'. London and New York: Routledge.

Håkansson, H. and A. Waluszewski, eds. 2007. 'Knowledge and Innovation in Business and Industry. The importance of using others'. London: Routledge.

Håkansson, H., D. Ford, L.-E. Gadde, I. Snehota, and A. Waluszewski. 2009. 'Business in Networks'. Chichester: Wiley and Sons.

Jacobsen, M. 2010. 'Interdependency Versus Notions of Decoupling in a Globalising World: Assessing the Impact of Global Economics and Industrial Developments and Inter-Ethnic relations in Penang, Malaysia'. Copenhagen Discussion Papers Series, No. 35.

Kaufmann, A., and T. Tödtling. 2002. 'How effective is innovation support for SMEs? An analysis of the region of Upper Austria'. Technovation 22(3): 147-159.

Kneller, R. 2010. 'Importance of new companies for drug discovery: Origins of a decade of new drugs. Nature Reviews Drug Discovery 9(November): 867-882.

Levy, D. 2008. 'Political Contestation in Global Production Networks'. Academy of Management Review 33(4): 943-963.

Liu, C.-Y. 1993. 'Government's role in developing a high tech industry - The case of Taiwan's semiconductor industry'. Technovation 13(5): 299-309.

Lundvall, B.- $\mathrm{A}$. 1988. 'Innovation as an interactive process: From user-producer interaction to the national innovation systems. In Technical Change and Economic Theory, G. Dosi, C. Freeman, R.R. Nelson, G. Silverberg, L. Soete (eds.), pp. 349-369. London: Pinter.

Mathews, J., and D.S. Cho. 2000. 'Tiger Technology - The creation of a Semiconductor Industry in East Asia'. Cambridge: Cambridge University Press.

MOEA (Ministry of Economic Affairs). 2007. 'Industrial Development in Taiwan, ROC'. Ministry of Economic Affairs. Taiwan, ROC.

MOEA. 2008. 'Introduction to Investment in the Biotechnology and Pharmaceutical Industries in Taiwan Republic of China'. Ministry of Economic Affairs, BPIPO. Taiwan, ROC.

MOEA. 2010. 'White Paper on SMEs in Taiwan, 2010'. Ministry of Economic Affairs. Taiwan, ROC.

Narula, R. 2004. 'R\&D collaboration by SMEs: New opportunities and limitations in the face of globalisation'. Technovation 24(2): 153-161.

OECD (Organization for Economic Co-operation and Development. 2010. 'SMEs, Entrepreneurship and Innovation'. OECD Studies on SMEs and Entrepreneurship. OECD Publishing.

Rosenberg, N. 1994. 'Path-dependent aspects of technological change'. In Exploring the 
Tommy Tsung Ying Shih

Black Box. Technology Economics, and History, by N. Rosenberg, pp. 1-6. Cambridge: Cambridge University Press.

Shih, T. 2009. 'Scrutinizing a policy ambition to make business out of science - Lessons from Taiwan'. Doctoral Dissertation, Department of Business Studies, Uppsala University.

Strömsten, T., and H. Håkansson. 2007. 'Resources in use: Embedded electricty'. In Knowledge and Innovation in Business and Industry. 'The importance of using others', $\mathrm{H}$. Håkansson and A. Waluszewski (eds.), pp. 27-53. London: Routledge.

Thornton, P.H. 2002. 'The rise of the corporation in a craft industry: Conflict and conformity in institutional logics'. Academy of Management Journal 45(1): 81-101.

Van de Ven, A., D. Polley, R. Garud, and S. Venkataraman. 1999. 'The Innovation Journey'. New York: Oxford University Press.

Walsham, G. 1995. 'Interpretive case studies in IS research: Nature and method'. European Journal of Information Systems 4: 74-81.

Waluszewski, A., E. Baraldi, Å. Linné, and T. Shih. 2009. 'Resource interfaces telling other stories about the commercial use of new technology: The embedding of biotech solutions in US, China and Taiwan'. IMP Journal 3: 86-123.

Wong, J. 2005. 'Re-Making the Developmental State in Taiwan: The Challenges of Biotech'. International Political Science Review 26(2): 169-191.

World Bank. 1993. 'The East Asian Miracle: Economic Growth and Public Policy'. Oxford: Oxford University Press. 